\title{
Osteoporosis case ascertainment strategies in European and Asian countries: a comparative review
}

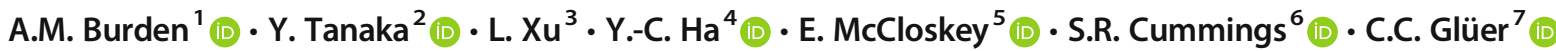

Received: 18 October 2020 / Accepted: 18 November 2020 / Published online: 10 December 2020

(C) The Author(s) 2020

\begin{abstract}
While many clinical guidelines recommend screening for osteoporosis for early detection and treatment, there is great diversity in the case-finding strategies globally. We sought to compare case-finding strategies, focusing on the approaches used in European and Asian countries. This article provides an overview of the current case-finding strategies in the UK, Germany (including Austria and German-speaking regions of Switzerland), China, Japan, and Korea. We conducted a review of current treatment guidelines in each country and included expert opinions from key opinion leaders. Most countries define osteoporosis among patients with a radiographically identified fracture of the hip or the vertebrae. However, for other types of fractures, or in the absence of a fracture, varying combinations of risk-factor assessment and areal bone mineral density (aBMD) assessed by dual Xray absorptiometry are used to define osteoporosis cases. A T-score $\leq-2.5$ is accepted to identify osteoporosis in the absence of a fracture; however, not all countries accept DXA alone as the sole criteria. Additionally, the critera for requiring clinical risk factors in addition to aBMD differ across countries. In most Asian countries, aBMD scanning is only provided beyond a particular age threshold. However, all guidelines recommend fracture risk assessment in younger ages if risk factors are present. Our review identified that strategies for case-finding differ regionally, particularly among patients without a fracture. More homogenized ways of identifying osteoporosis cases are needed, in both the Eastern and the Western countries, to improve osteoporosis case-finding before a fracture occurs.

Case-finding in osteoporosis is essential to initiate treatment and minimize fracture risk. We identified differences in casefinding strategies between Eastern and Western countries. In the absence of a diagnosed fracture, varying combinations of risk factors and bone density measurements are used. Standardized case-finding strategies may help improve treatment rates.
\end{abstract}

Keywords Case-finding $\cdot$ Osteoporosis $\cdot$ Review $\cdot$ Treatment

\section{Introduction}

Osteoporosis is one of the most common diseases of aging, with an increasing prevalence of disease and fractures with

A.M. Burden

andrea.burden@pharma.ethz.ch

1 Department of Chemistry and Applied Biosciences, Institute of Pharmaceutical Sciences, ETH Zurich, Vladimir-Prelog-Weg 4, CH-8093 Zurich, Switzerland

2 University of Occupational and Environmental Health, Japan, 1-1, Iseigaoka, Kitakyushu 807-8555, Japan

3 Department of Obstetrics and Gynecology, Peking Union Medical College Hospital, Beijing 100730, People's Republic of China age [1]. The worldwide prevalence of osteoporosis is difficult to ascertain due to differing definitions and diagnostic criteria. However, one-in-four women and one-in-eight men aged 50 years or older have osteoporosis [2]. If these proportions are

4 Department of Orthopaedic Surgery, Chung-Ang University College of Medicine, 102 Heukseok-ro, Dongjak-gu, Seoul 06973, South Korea

5 Metabolic Bone Centre, United Kingdom, Sorby Wing, Northern General Hospital, Herries Road, Sheffield 557AU, UK

6 San Francisco Coordinating Center, Sutter Health and the Department of Epidemiology and Biostatistics, University of California, San Francisco, Mission Hall: Box \#0560, 550-16th Street, 2nd Floor, San Francisco, CA 94143, USA

7 Section Biomedical Imaging, Department of Radiology and Neuroradiology, Christian-Albrechts-University, Am Botanischen Garten 14, 24118 Kiel, Germany 
extrapolated to the current world population statistics [3], over 228 million adults aged 55 years or older would have osteoporosis, which is a marked increase from the previous estimate of 200 million in 2006 [4].

Characterized by a gradual loss in areal bone mineral density (aBMD) and deterioration of bone microarchitecture, clinically osteoporosis leads to increased bone fragility and subsequent fragility fractures - typically of the forearm, humerus, vertebra, and hip (femur and femoral neck). Osteoporotic fractures, in particular hip fractures, have an important and serious health impact leading to significant increases in mortality, pain, and loss of independence [5, 6]. Importantly, osteoporosis is a silent disease as patients are often unaware of the disease progression due to a lack of observable symptoms until a fall or an impact of an adequate force results in a bone fracture. Therefore, identifying individuals with increased risk of experiencing a fracture is crucial for early intervention and minimization of fracture risk. This applies to all fractures, regardless of the level of aBMD [7]. However, despite acknowledging the negative consequences of fractures, such as reductions in quality of life and higher mortality associated with fracture $[5,6]$ and the efficacy of treatment to reduce risk, osteoporosis remains widely under-diagnosed and undertreated [8-11].

Thus, while there are several country-specific guidelines to identify those patients at increased risk of fractures, there is great diversity in the case-finding strategies globally, particularly between eastern and western countries $[12,13]$. To address these differences, this narrative review by members of the East-meets-West working group within the European Calcified Tissue Society (ECTS) aims to summarize the case-finding strategies in osteoporosis, with a focus on a comparative review between a selection of Asian and European countries - including China, Japan, South Korea, the UK, and German-speaking countries (Germany, Austria, a Swissspeaking Switzerland).

\section{Introduction to case-finding}

Osteoporosis is most commonly classified using the World Health Organization (WHO) operational definition and based on aBMD measurement using dual X-ray absorptiometry (DXA), relative to the aBMD of an average young adult [14-16]. Using this approach, osteoporosis patients are those with an aBMD in the femoral neck (hip), spine, or forearm that is 2.5 standard deviations or more below that of the mean of healthy young adult females (the so-called T-score) [14]. Fracture risk decreases exponentially with increasing aBMD, and low aBMD is a strong predictor of fracture of multiple types, even over more extended periods [17]. However, it is well established that fractures can occur in patients without an aBMD T-score of -2.5 and below. Indeed, since there are many more subjects with an aBMD T-scores above -2.5 than with an aBMD T-score below -2.5 , most fractures occur in people with BMD T-score > -2.5 [18]. Consequently, clinical factors such as age, sex, family history, smoking status, and physical activity, along with disorders or medications with a negative impact on bone, likely play important roles in fracture risk and should be included in the case-finding assessment.

Indeed, using aBMD alone to identify patients at risk for a fracture will likely have poor sensitivity as many patients at risk for a fracture will not be identified and thereby not offered therapeutic management. Technically, aBMD as a projection measure is affected by body size, but definitions based on volumetric BMD, assessed by quantitative computed tomography (QCT), also show limited sensitivity. More importantly, there are a number of disorders other than osteoporosis, where aBMD is also substantially reduced (e.g., multiple myeloma or osteogenesis imperfecta), thereby pointing out the need for differential diagnosis. DXA-based aBMD assessment is, therefore, an indicator of bone mass-related fracture risk as opposed to fracture risk resulting from extra-skeletal factors, such as a propensity for falling or due to deteriorated bone material properties. This reflects a strength (low aBMD indicates the need to target treatment to the bone) and a weakness (limited capability to identify risks due to causes other than bone mass deficits) of using DXA alone to identify osteoporosis. Thus, low aBMD should be considered a risk factor for fracture rather than a singular definition of osteoporosis. Accordingly, considering aBMD, in addition to other clinical risk factors, will increase fracture risk assessment accuracy.

Several clinical tools have been developed to calculate an individual's risk of fracture in light of this. The most widely used tool is the fracture risk assessment tool FRAX® (www. shef.ac.uk/FRAX). Developed at the University of Sheffield in the UK, FRAX® estimates the 10-year probability of major osteoporotic (hip, forearm, proximal humerus, and clinical vertebral) and hip fracture. The FRAX® algorithm determines the fracture probability by integrating the weight of important clinical risk factors, with or without an aBMD measurement. In the UK, the SCreening for Osteoporosis in Older women for the Prevention of fracture [SCOOP] study tested whether risk-based screening using FRAX® effectively reduced fracture incidence $[19,20]$. The study was a community-based screening intervention of 12,483 women aged 70 to 85 years in the UK. In the screening arm, licensed osteoporosis treatments were recommended in women identified to be at high risk of hip fracture using the FRAX ${ }^{\circledR}$ risk assessment tool (including aBMD measurement). In the control arm, standard care was provided. Screening led to a significant $28 \%$ (adjusted hazard ratio [aHR] $0.72,95 \%$ confidence interval [CI] 0.59-0. 89) reduction in hip fractures over 5 years, with no overall reduction in fracture risk [19]. 
Another study testing whether a FRAX®)-based risk assessment effectively reduced fracture incidence in the Danish Riskstratified Osteoporosis Strategy Evaluation (ROSE) study [21, 22]. Here, patients were randomized before the invitation to screening was sent out. Participants filled out a questionnaire to calculate the FRAX® 10-year risk of major osteoporotic fracture. Researchers did not inform women in the control group about the result of the FRAX calculation. In contrast, women in the intervention group, with a $\geq 15 \%$ risk, were invited to undergo DXA scanning. The woman and her general practitioner (GP) received the examination results by letter. The information included treatment recommendations based on the Danish national guidelines; however, the patient and GP made the treatment decisions. The primary intention-to-treat analysis of the 34,229 women aged 65-80 years showed no significant overall effect on major osteoporotic fracture (aHR $0.99,95 \%$ CI 0.92-1.06) or hip fracture (aHR 1.00, 95\% CI 0.89-1.13) between those randomized to the screening group compared to the control group. However, a pre-planned per-protocol analysis, among only those who returned the questionnaire with sufficient information to calculate FRAX®, showed a slight risk reduction in the screening group compared to women in the control group for major osteoporotic fracture (aHR 0.91, 95\% CI 0.83-1.01) and hip fracture (aHR 0.82, 95\% CI 0.67-1.01). However, compared to controls with a FRAX® $\geq 15 \%$, the screening group showed a significant reduction in major osteoporotic fractures (aHR $0.87,95 \%$ CI $0.77-0.99$ ) and hip fractures (aHR 0.74, 95\% CI 0.58-0.95) was observed [21]. However, we note that a self-selection bias may be present in the per-protocol analyses.

While the SCOOP study and the per-protocol analyses in the ROSE study support the notion that screening for fracture risk is associated with a significant risk reduction for hip fractures, the SALT Osteoporosis Study (SOS) from the Netherlands failed to find a similar conclusion [23]. This study included only women aged 65 to 90 years, with more than one clinical risk factor for fracture. Women with a high 10-year FRAX® risk, or a prior vertebral fracture, were offered osteoporosis treatment. Among the 5575 patients in the screening group, 25\% ( $n=1417)$ indicated to receive osteoporosis treatment, yet during follow-up, there was a non-significant effect on fracture risk, including hip fracture (aHR 0.91, 95\% CI 0.1-1.15) [23]. However, unlike the SCOOP or ROSE studies, the definition of the high-risk group is unclear, and there are important caveats that may underestimate the effect of screening programs [24].

Since 2008 when the FRAX® tool was launched, it has been diversified for use in 63 countries, currently 35 European countries and 11 countries/regions in Eastern Asia, with each tool calibrated based on estimates of the national hip fracture and mortality epidemiology. Currently, calibrated FRAX ${ }^{\circledR}$ models are available for 58 countries globally [25]. A comprehsive overview of these can be identified in systematic reviews by the National Osteoporosis Guideline Group and the International Osteoporosis Foundation (IOF) [25]. Importantly, as it was primarily developed in Caucasian populations $[25,26]$, FRAX ${ }^{\circledR}$ may overestimate the fracture risk in minority populations (including Asian, African, and Hispanic populations) [27]. Thus, local calibration is pertinent. A discussion of the strengths and limitations of FRAX® is available elsewhere [27]. For example, in contrast to hip fractures, data on the incidence of other fractures is limited. Thus, to construct a FRAX® tool in the absence of such data, it is assumed that the ratio of hip fractures to other types of fractures is similar across populations. While true in Caucasians, this needs to be confirmed in other ethnicities. For example, in elderly (> 65 years) Hong Kong Chinese and Japanese individuals, the ratio of vertebral fractures to hip fractures may be higher [28].

Currently, FRAX® is widely used, particularly in China, Hong Kong, Japan, South Korea, and Taiwan, where there are population-specific FRAX ${ }^{\circledR}$ algorithms. Limited access to DXA in some countries remains an issue, with some adopting the use of quantitative ultrasound (QUS) measurements. To date, FRAX® does not accommodate the QUS [29, 30]. Additionally, other screening tools developed to calculate the likelihood of underlying osteoporosis rather than fracture risk are available. Examples include the Osteoporosis Self-Assessment Tool for Asians (OSTA) or the IOF 1-min questionnaire, which simply detects the presence of risk factors associated with osteoporosis. Such tools have been implemented in China to identify those at risk for osteoporosis, thereby optimizing DXA scan use given limited resources [31].

\section{Geographical variations in case-finding strategies}

\section{China}

\section{Osteoporosis burden}

The size of the aging population in China is growing rapidly, and consequently, osteoporosis is becoming one of the country's largest health problems. A recent study identified that, among those aged 65 years or older, the hip fracture rate increased substantially from the early 1990 s to 2006 [32]. Thus, osteoporosis case-finding to prevent fractures and minimize the associated costs has emerged as a high priority.

\section{Osteoporosis case-finding strategies}

To tackle the challenge of identifying and treating osteoporosis, physicians complete a two-phase case-finding approach. The approach is in accordance with the guidelines for primary 
Table 1 Criteria for aBMD assessment or vertebral fracture risk assessment in China

\begin{tabular}{|c|c|}
\hline aBMD measurement & Vertebral fracture assessment \\
\hline $\begin{array}{l}\text { (1) over } 65 \text { (women) or } 70 \text { (men) years of age, } \\
\text { (2) }<65 \text { (women) or }<70 \text { (men) years with one or more major } \\
\text { risk factors for osteoporosis: } \\
\cdot \text { Fragility fracture } \\
\text { •Hypogonadism } \\
\text {-Radiograph with the manifestation of osteoporosis } \\
\text { - Receive osteoporosis pharmacotherapy } \\
\text {-Diagnosis of disease influencing bone metabolism } \\
\text {-IOF 1-min questionnaire with “+" indicated for questions } \\
\text { requiring "greater than" responses } \\
\text {-OSTA score } \leq-1\end{array}$ & $\begin{array}{l}\text { (1) Women } \geq 70 \text { years and men } \geq 80 \text { years with } \\
\text { an aBMD T-score } \leq-1 \\
\text { (2) Women } 65-69 \text { years, and men } 70-80 \text { years } \\
\text { with an aBMD T } \leq-1.5 \\
\text { (3) Adults ( } \geq 50 \text { years) with one of the } \\
\text { following: } \\
\text { a Fragility fracture } \\
\text { b Height decrease of } \geq 4 \mathrm{~cm} \text {, as compared to } \\
\text { peak adult height } \\
\text { c Height decrease of } \geq 1 \mathrm{~cm} \text { within } 1 \text { year } \\
\text { d Glucocorticoid therapy } \geq 3 \text { months }\end{array}$ \\
\hline
\end{tabular}

$a B M D$, bone mineral density; IOF, International Osteoporosis Foundation; OSTA, Osteoporosis Self-Assessment Tool for Asians osteoporosis provided by the Chinese Society of Osteoporosis and Bone Mineral Research (CSOBMR) founded under the Chinese Medical Association [33]. Under these guidelines, a first case diagnosis is determined based on a history of known fractures. Thus, those with an identified fracture receive a diagnosis of osteoporosis and medical treatment recommendation. Those without a known fracture, radiographic imaging for a suspected vertebral fracture, and aBMD measurement using DXA for osteoporosis diagnosis are considered. Similarly, if a vertebral fracture is identified, or an aBMD Tscore $\leq-2.5$ is observed, the diagnosis of osteoporosis is established. An overview of the criteria for receiving aBMD or radiographic assessment to identify osteoporosis cases is provided in Table 1.

Additionally, in the absence of a fracture, further risk assessment can be conducted to identify patients at risk for osteoporotic fractures. Here, the risk assessment is multifaceted and includes the International Osteoporosis Foundation (IOF) 1-min questionnaire for risk of osteoporosis assessment [34], the Osteoporosis Self-assessment Tool for Asians (OSTA: weight in kilograms - age in years] * 0.2), FRAX® (for China) [35], falls, and other risk factors. For patients with $\mathrm{T} \leq-2.5$ and patients with $-2.5<\mathrm{T}$-score $<-1$, if FRAX® risk $\geq 20 \%$ for major osteoporotic fractures or $\geq 3 \%$ for hip fractures, osteoporosis therapy is indicated. Figure 1 provides a depiction of the risk assessment procedure.

\section{Japan}

\section{Osteoporosis burden}

Approximately $28 \%$ of the population is aged 65 years or older, and the estimated prevalence of osteoporosis is 15
Fig. 1 Flow-chart of the risk assessment strategy for identifying osteoporosis cases in patients without a known fracture in China

Abbreviations: IOF: International Osteoporosis Foundation; OSTA: Osteoporosis Self-Assessment Tool for Asians; T: T-score; FRAX: fracture risk assessment tool (www.shef.ac.uk/FRAX)

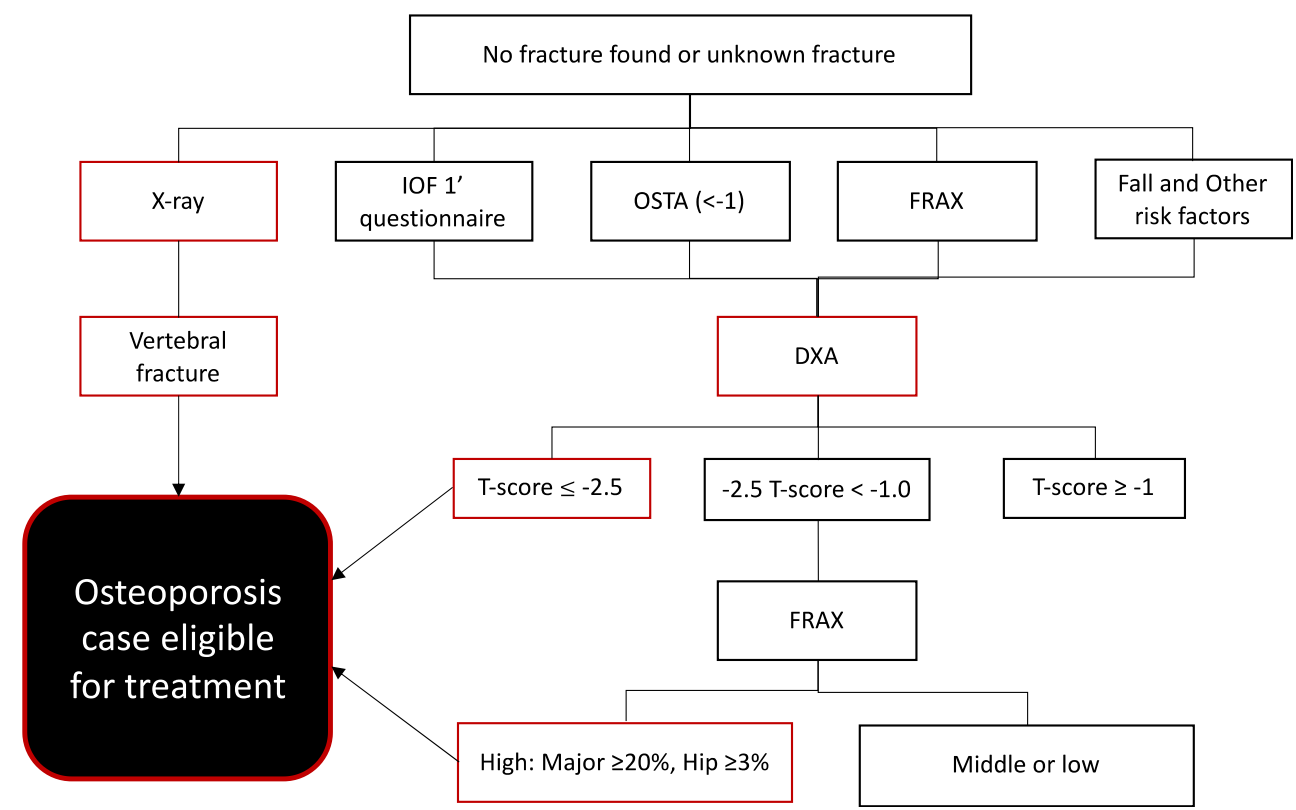


million individuals, resulting in roughly 200,000 hip fractures annually [36-38]. Despite attention to the need for improved screening services and education on osteoporosis, screening rates for osteoporosis remain low compared to other chronic diseases [39]. While historically osteoporosis screening is deprioritized due to financial reasons, a recent economic analysis concluded that DXA screening for case-finding based on age and risk factors would be cost-effective in Japan.

\section{Osteoporosis case-finding strategies}

In Japan, diagnostic criteria for osteoporosis follow the 2011 guidelines for the prevention and treatment of osteoporosis [39]. Here diagnostic criteria for osteoporosis are based on medical interviews, physical examinations, diagnostic imaging, and blood and urine analysis [39]. Following an initial assessment, patients receive further aBMD measurement and a lateral spine radiograph, if deemed necessary by the clinician. Osteoporosis diagnosis, and treatment recommendations, occur among patients with a defined fragility fracture of the hip and/or vertebrae, and no alternative diagnosis (Fig. 2). We note that the Japanese guidelines were the only to define and focus on "fragility" fractures.

All other patients require further fracture and aBMD assessment before a treatment decision. Among patients with a non-hip or non-vertebral fragility fracture, treatment is recommended among those with an aBMD less than $80 \%$ of the young adult mean in women (YAM), the equivalent of a DXA T-score of - 1.5 [39]. In the absence of a fragility fracture, osteoporosis treatment initiation occurs among those with aBMD less than $70 \%$ of YAM (equivalent to DXA Tscore of -2.5 ). In comparison, those with aBMD between 70 and $80 \%$ of YAM require further clinical assessment. Among the latter, those with a 10 -year FRAX® probability of major fracture $\geq 15 \%$, or those with a family history of hip fractures, initiate treatment, Fig. 2. We note that the relationship between the YAM and T-score cut-off values has shifted over time. In 2008, it was identified that an aBMD measurement of $70 \%$ and $80 \%$ of the YAM in Japan was equivalent to a Tscore between -2.7 and -1.8 , respectively [40]. However, since the release of the 2011 osteoporosis treatment guidelines [39], cut-off values associated with aBMD between 70 and $80 \%$ of the YAM have been updated to internationally recognized standards of -2.5 and -1.5 , respectively [41].

\section{Korea}

\section{Osteoporosis burden}

South Korea became an aging society in 2000, with those aged 50 years or older comprising approximately $7 \%$ of the total population. In 2018, South Korea is now an aging society

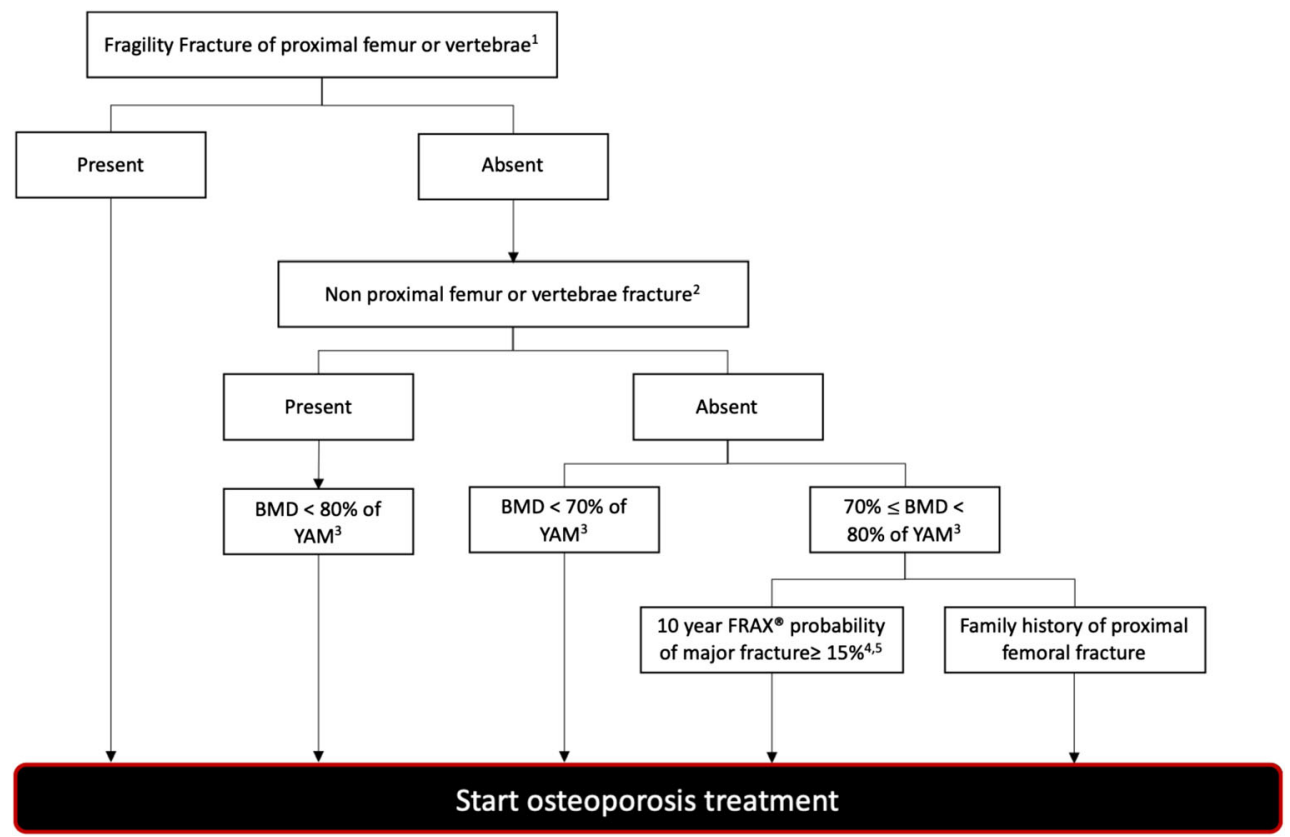

Fig. 2 Criteria for initiation of pharmacological treatment for osteoporosis in Japan (adapted from Orimo et al. [39]). Abbreviations: aBMD: bone mineral density, YAM: young adult mean for women; FRAX: fracture risk assessment tool FRAX® (www.shef.ac.uk/FRAX). ${ }^{1}$ proximal femur (hip) fracture and/or vertebral fracture caused by a slight external force after menopause in women and after age 50 in men. ${ }^{2}$ distal forearm, proximal humerus, pelvis, lower leg, and/or rib fracture caused by a slight external force after menopause in women and after age 50 in men. ${ }^{3}$ revision of additional T-scores is under consideration for some measurement sites. An aBMD less than $70 \%$ of YAM is equivalent to DXA T-score of $-2.5 .{ }^{4}$ applied in persons $<75$ years. Additionally, a lower cut-off value does not include all young persons in and around their 50 s for whom pharmacological treatment is recommended based on the present diagnostic criteria. ${ }^{5}$ critera should be applied only to persons who answer "No" to FRAX ${ }^{\circledR}$ risk factors of "glucocorticoid," "rheumatoid arthritis," or "secondary osteoporosis" 
with $\geq 14 \%$ of the full population aged 50 years or older, and by 2026 , it is projected that Korea will be a super-aged society defined as $\geq 20 \%$ of the total population being aged 50 years or older [42]. In line with the aging population, South Korea experienced a substantial $47.3 \%$ increase in the number of osteoporotic fractures in patients aged 50 years or older between $2008(n=146,240)$ and $2011(n=215,460)$ [43]. The incidence of hip, vertebral, radius, and humerus fracture increased more among women than men during this time [44] [45-47]. Similarly, between 2008 and 2011, a study identified that the total healthcare costs associated with fractures increased by $31.6 \%$ from $\$ 549$ million to $\$ 722$ million, respectively [48]. Depending on the fracture type, the most expensive fracture for both genders was a vertebral fracture, accounting for 43 to $45 \%$ of the total costs [48].

\section{Osteoporosis case-finding strategy}

Despite the growing elderly population and increased fracture burden, osteoporosis is currently not considered a national priority in Korea. Consequently, the government has not produced official national guidelines on osteoporosis. However, the Korean Society for Bone and Mineral Research (KSBMR) has published its own Physician's guide for diagnosing and treating osteoporosis in 2007, with updates in 2008, 2011,
2013, 2015, 2018, and 2019 [49]. The guidelines offer criteria for osteoporosis diagnosis and treatment recommendations.

The guidelines currently recommend a diagnosis of osteoporosis, and osteoporosis treatment initiation, for all patients aged 50 years or older who have a prior fragility fracture. Since May 2015, patients with a fracture, diagnosed by a physician and confirmed via X-ray, do not require a diagnosis of osteoporosis via DXA (T-score of $\leq-2.5$ from aBMD) to be eligible for treatment. Under this guideline, patients receive coverage for medical treatment costs over a period of 3 years [50].

Patients aged 50 years or older who do not have a fracture require additional assessments before diagnosis. There is a recommendation for a DXA test for women aged 65 years or older and men aged 70 years or older. Following DXA screening, the guideline recommends treatment initiation among those with aBMD T-score value of - 2.5 of the lumbar spine, femur, femoral neck, or total hip [49]. Additionally, since 2019, osteoporosis treatment is recommended for patients taking prednisolone $\geq 2.5 \mathrm{mg}$ for 3 months or longer with a T-score of -1.5 of the lumbar spine, femur, remoral neck, or total hip. Additionally, men under 50 years and pre-menopausal women taking prednisolone $\geq 2.5 \mathrm{mg}$ for 3 months or longer with a Zscore of -3.0 of the lumbar spine, femur, femoral neck, or total hip should receive treatment [51]. Figure 3 depicts the casefinding and treatment recommendation strategy.
Fig. 3 Overview of osteoporosis case-finding strategy in Korea. Abbreviations: DXA: dual X-ray absorptiometry, LS: lumbar spine, FN: femoral neck, GC: glucocorticoid, M: month, mg/d; milligrams per day

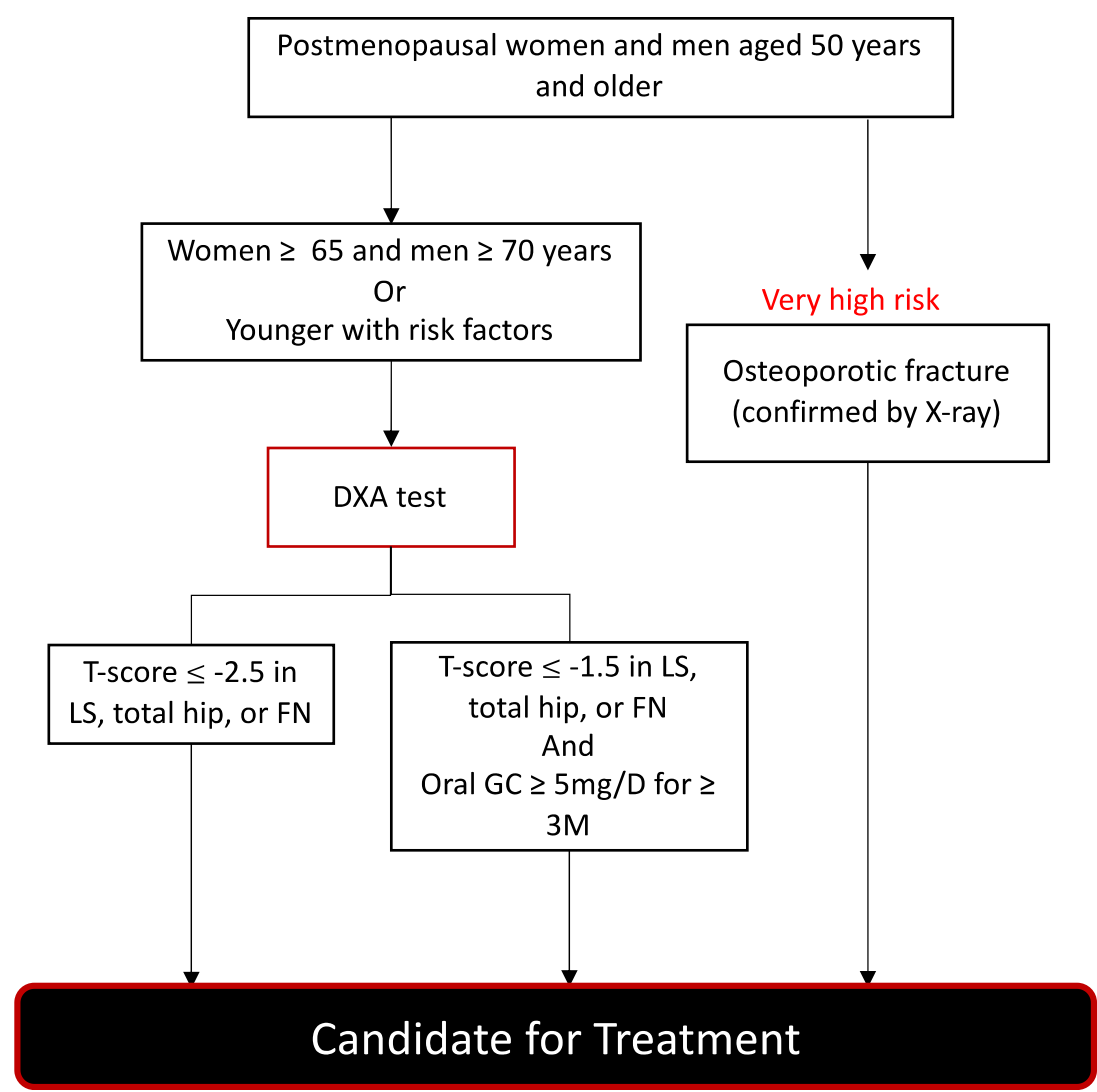




\section{The UK and European German-speaking countries}

\section{Osteoporosis burden}

A 2013 review by the IOF estimated that 22 million women and 5.5 million men had osteoporosis across Europe, which resulted in 610,000 hip fractures, 520,000 vertebral fractures, and $>2$ million other fractures (e.g., forearm, pelvis, rib, humerus, tibia, fibula, clavicle, scapula, sternum, or hip) [52]. The most recent estimates suggest the prevalence of osteoporosis among those over 50 years of age in six large European countries (France, Germany, Italy, Spain, Sweden, and the UK) is approximate $7 \%$ for men and $22 \%$ for women, with fracture-related costs of 37.5 billion Euros in 2017 [53].

\section{Osteoporosis case-finding strategies in the UK}

Most European countries promote a case-finding FRAX-based approach, with fracture risk calculated in those with identifiable risk factors, however not all identify thresholds for treatment based on FRAX® alone. FRAX® does not specify treatment thresholds, so that further interpretation and application of assessment and intervention thresholds are needed. Guidance from the IOF proposed a treatment threshold equivalent to a FRAX®-based 10-year probability of a major osteoporotic fracture of a woman with a previous fracture (no other clinical risk factors, a body mass index $24 \mathrm{~kg} / \mathrm{m}^{2}$, and without aBMD).
This treatment threshold would increase with age up to about age 85 , after which it levels off due to high mortality [15, 54]. This approach was first proposed by the National Osteoporosis Guideline Group (NOGG) in the UK [55]. Under the NOGG criteria, patients with a history of a fragility fracture should receive treatment without the need for further assessment. However, at younger ages, additional aBMD may be appropriate. Among those without a fracture, age-dependent intervention thresholds are applied up to 70 years, after which there are fixed thresholds [55]. The plateau at age 70 reduces inequalities in fracture risk required for treatment in those without a prior fracture. Before the application of the plateau, older women without fracture required a higher fracture risk to receive treatment compared to those with a prior fracture [56].

\section{Case-finding strategies in German-speaking regions}

Not all European countries have adopted this age-related intervention threshold, in the belief that it appears to impose a relatively high threshold for treatment in the most elderly. For instance, the Dachverband Osteoporose (DVO) [57], the umbrella organization on osteoporosis for the German-speaking countries of Austria, Germany, and Switzerland, has developed the DVO Osteoporosis Guidelines. These guidelines specify constant diagnostic and therapeutic thresholds independent of age and gender to avoid over-treating younger patients and under-treating elderly ones. These thresholds

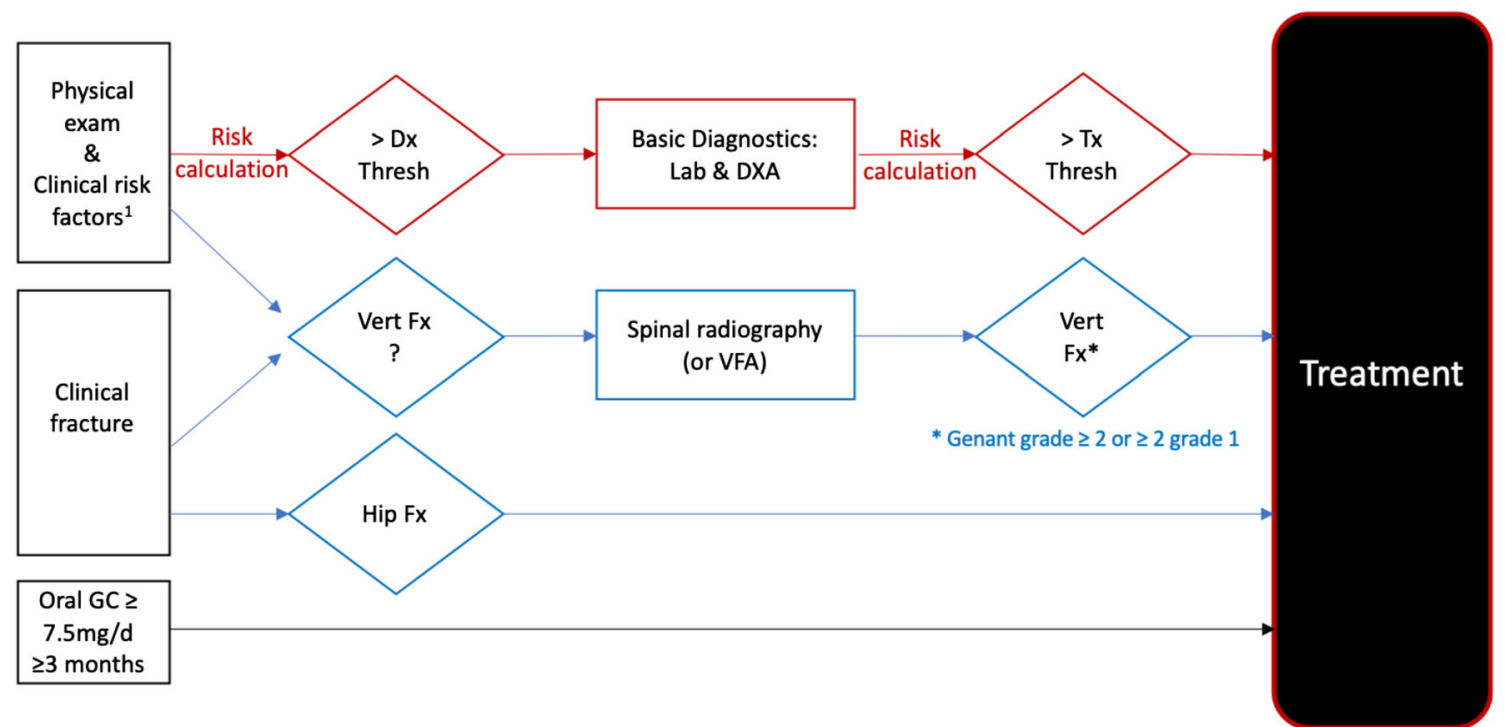

Fig. 4 Flow-chart of the osteoporosis case-finding strategy of the Dachverband Osteologie (DVO) for Germany, Austria, and Germanspeaking Switzerland. Risk is based on the incidence of a hip or vertebral fracture; diagnostic (Dx) and therapeutic (Tx) thresholds that are constant, independent of age. For patients with osteoporotic fractures of the spine (see notel above) or hip and for patients on oral glucocorticoid treatment of $7.5 \mathrm{mg}$ prednisolone equivalent for $\geq 3$ months treatment is recommended. For all others, a two-stage approach is used to assess fracture risk based on aBMD and clinical risk factors. The diagnostic threshold is equivalent to the fracture risk of a woman in the general population of the age of 68 . The treatment threshold is equivalent to the fracture risk of a woman in the general population of the age of 74. Basic diagnostic laboratory tests include serum calcium, serum phosphate, alkaline phosphatase (AP), gamma GT, creatinine, C-reactive protein, TSH, serum-protein electrophoresis, hemogram, and vitamin D3. ${ }^{1}$ An overview of the clinical risk factors can be found in Thomasius et al. [57]. Abbreviations: Fx: fracture, Dx: diagnosis, DXA: dual X-ray absorptiometry, VFA: vertebral fracture assessment, GC: glucocorticoid 
are based on the incidence of hip or (radiographical or clinical) vertebral fractures.

Figure 4 presents the approach for case-finding by the DVO. Patients with osteoporotic ("low-trauma") fractures of the hip or spine, or taking oral glucocorticoid therapy, can be directly considered for treatment. For all others, case-finding is a two-stage procedure. First, based on numerous clinical risk factors [57], the patient's risk is estimated. Second, if the risk exceeds a diagnostic threshold (equivalent to the fracture risk of a woman in the general population of about age 68), DXA and lab examinations, and optionally fracture assessment by radiography, are indicated. After considering these examinations, osteoporosis treatment recommendation is made if aBMD $\leq-2$ and the risk exceeds the therapeutic threshold (equivalent to the fracture risk of a woman in the general population of about age 74).

\section{Challenges in osteoporosis case-finding}

Universally, one of the primary goals in osteoporosis management is adequate case-finding to ensure that patients at risk for fracture receive the appropriate therapies. However, to date, we have not realized optimal osteoporosis identification and management, as numerous studies have shown the low uptake of osteoporosis treatment following a fragility fracture [8-11]. One key barrier may relate to a continued lack of appreciation of the burden imposed by fragility fractures from all frontsgovernment, physicians, and patients, thereby leading to a lack of financial investment in resources and an under-diagnosis/under-assessment of at-risk patients. Moreover, with an aging population comes an increasing burden of chronic diseases in the elderly. Consequently, conducting multiple disease screenings is time-consuming, and osteoporosis casefinding may be deprioritized compared to cancer or cardiovascular risk. As seen in Japan, screening for cancer is $>30 \%$, while screening for osteoporosis is $\sim 4 \%[39,58]$. This is concerning in light of a previous US study that identified the hospitalization costs associated with osteoporotic fractures for women aged 55 years or older were higher than that of myocardial infarction, stroke, or breast cancer [59].

While the diagnosis of osteoporosis in the absence of a fracture may be time-consuming and could explain suboptimal treatment initiation rates, it is noteworthy that treatment initiation after a fracture also remains suboptimal worldwide. This is despite evidence that bisphosphonate use is associated with a decreased risk of subsequent fracture [60]. Indeed Solomon et al. previously identified that only $21 \%$ of patients with a hip fracture in 2011 received anti-osteoporosis therapy after a hip fracture [9]. In another US study, the rate of patients initiating (newly treated) osteoporosis treatment following a fracture has decreased over time [10]. In their study, Desai and colleagues found that treatment initiation following a hip fracture was $9.8 \%$ in 2004, and only $3.3 \%$ in 2015 [10]. In comparison, following a myocardial infarction, over $90 \%$ of patients are initiated on antithrombotic therapy (e.g., statins). Given the high morbidity, disability, and mortality following osteoporotic hip fractures, it is essential to improve osteoporosis treatment rate following a fracture. As noted above, the restriction to consider treatment among only low-trauma fractures may have led to reduced therapy rates. Importantly, we note that the guidelines reviewed here showed inconsistent terminology to define treatment indicators and additional fracture risk. For example, the guidelines used the terms fracture, low-trauma fracture, fragility fracture, or osteoporotic fracture to define osteoporotic fractures, and occasionally excluded specific fracture sites (e.g., cervical vertebrae, hand, foot). Homogenizing these terms and definitions may require further consideration and consensus finding.

While we observed that FRAX® is generally the preferred algorithm for the prediction of fracture risk to identify osteoporosis cases and determine treatment initiation, additional tools may help supplement fracture prediction and improve case-finding. For example, trabecular bone score (TBS) permits estimation of skeletal microstructure that cannot be captured from a standard aBMD measurement [61]. A recent meta-analysis identified that TBS provides additional information beyond FRAX ${ }^{\circledR}$ in both men and women, and across multiple ethnicities [62]. The meta-analysis included 14 cohort studies, including the Japanese Population-based Osteoporosis Study (JPOS), the MrOS Hong Kong study of Chinese men and women, the Osteoporosis and Ultrasound Study (OPUS) with participating centers in the UK and Germany, and the Swiss Evaluation of Methods of Measurement of Osteoporotic Fracture Risk (SEMOF). In each of these cohorts, TBS independently contributed to the assessment of fracture [62]. FRAX® provides an option to add TBS results and calculate the impact on fracture risk. It is expected that supplementing FRAX® with TBS will further improve fracture prediction. Additionally, there is growing evidence that TBS and other FRAX®-based aglorithms, including the Derived FRAX (DeFRA), may also improve casefinding strategies in high-risk sub-populations, such as patients with diabetes $[63,64]$.

Another promising opportunity for improving osteoporosis case-finding and subsequent treatment initiation following a fracture is the expansion of fracture liaison services (FLS) globally [65]. Notably, the IOF Capture the Fracture campaign highlighted the importance of FLS services [66]. A similar position paper in Europe, by the European League Against Rheumatism (EULAR) and the European Federation of National Associations of Orthopaedics and Traumatology (EFFORT), further supports FLS for fracture management and treatment monitoring [67]. Additionally, we note the promotion of healthcare consortiums, such as the World Health Organization (WHO) Network for Prevention and Management of Osteoporosis [68]. This initiative would 
coordinate the network between community health services and hospitals. Case-finding and risk assessment may be completed at the community level, while the hospitals would provide diagnosis and treatment. A recent meta-analysis of clinical trials and observational studies further supports FLS. The meta-analysis identified that FLS programs improved treatment initiation and reduced re-fracture and mortality rates [69].

Within Asia, similar efforts are being made to mitigate the healthcare burden of fractures resulting from under-diagnosed osteoporosis. For example, the Chinese Ministry of Health implemented the Win Over Osteoporosis (WOO) project in 2009, which focuses on enhancing the education of osteoporosis and screening for diagnosis for high-risk patients. In Japan, the opening of osteoporosis liaison services (OLS) has been established by the Japan Osteoporosis Society since 2015. The primary mission of OLS is to provide educational programs, medical check-ups for bone fragility, improve medication adherence, and risk assessment for primary and secondary fracture in osteoporotic subjects. While large studies are lacking, an OLS site assessment found significantly improved osteoporosis diagnosis after OLS in patients with hip fractures [70]. In South Korea, hip fracture registry programs have been operating since 2014, and FLS since 2016. The emphasis on early detection and treatment of osteoporosis in Korea by the National Health Examination (NHE) has resulted in a doubling of aBMD examinations for women aged 54 years and 65 years old since 2018 [71].

Finally, osteoporosis is still predominantly viewed as an older women's disease as fractures are more common in women than in men. Consequently, studies of osteoporosis case-finding and fracture prevention are primarily among post-menopausal women. While osteoporosis is less common in men, approximately $6 \%$ of men aged 50-84 years have osteoporosis in Europe, with similar numbers observed in Asia [52, 72]. Additionally, about $30 \%$ of osteoporotic fractures occur in men, and the mortality rate following a hip fracture among patients aged 70 years or older is more than double that in women [4]. The first step to overcome this is to expand the recognition and research, such as the MrOs study [73, 74], among men. The MrOs study has been conducted in sites in the USA, Hong Kong, and Sweden, permitting comparisons across continents [75, 76]. Likely, a similar two-phase case-finding strategy, as seen in many countries, can be adopted - whereby the existence of a prior fracture stratifies men. Similar to women, men aged 50 years or older with a fracture, and in the absence of an alternative diagnosis, should be considered for osteoporosis therapy. In the absence of fracture, male patients should receive additional screening to assess risk factors. However, as the evidence suggests male fracture risk increases approximately 10 years after women, we suggest that the age for case-finding in the absence of a fracture should be older among men than in women [77].

\section{Summary}

Optimized case-finding strategies are essential for adequate osteoporosis assessment and therapy. A review of the case-finding strategies and guidelines used by five countries (China, South Korea, Japan, the UK, and Germany-including Austria and German-speaking Switzerland) indicates substantial discrepancies, particularly in the absence of a fracture. While most countries have similar approaches in the presence of a radiographic-confirmed hip or vertebral fracture, differences emerge in the absence of a fracture. Most guidelines favor a two-stage procedure, first assessing clinical risk factors, with a more detailed investigation of the bone status including DXA only recommended among those at higher risk. The method to handle differential diagnosis also differs.

Notably, the thresholds for osteoporosis treatment vary substantially from country to country. An overview of the different treatment thresholds by country is provided in Table 2. Similar to the case-finding approach, all countries recommend osteoporosis therapy initiation following a fracture of the hip or spine. Again, in the absence of a fracture, the approaches differ. While most, but not all, countries mandate the assessment of aBMD using DXA, the threshold for treatment is not uniform. In China, Japan, and South Korea, a threshold of $\mathrm{T} \leq-2.5$ is sufficient to initiate treatment. However, both the Chinese and Japanese guideliens require additional risk factors in patients with a T-score between -2.5 and 1.0 indicating osteopenia, while this is not specified in the South Korean guidelines. In Europe, an aBMD in the osteoporotic range by itself may not be sufficient to initiate therapy. Rather, the fracture risk has to reach a specific level that can be independent (GermanAustrian-Swiss) or dependent on the age (UK) of the patient. In the UK, high fracture risk due to a specific constellation of risk factors can be sufficient to indicate the need for treatment, even in the absence of DXA results. In China and Japan, FRAX® is only used as an indicator of osteoporosis definition and treatment initiation if aBMD indicates osteopenia, i.e., an aBMD between a T-score of -1 and -2.5 . Additionally, only South Korea, the UK, and the German DVO specify oral glucocorticoid use thresholds as independent factors for osteoporosis treatment initiation. 
Table 2 Indication for osteoporosis-specific medications for post-menopausal women and men aged 50 years or older, stratified by country

\begin{tabular}{|c|c|c|c|c|c|}
\hline & China & Japan & Korea & $\mathrm{D}-\mathrm{A}-\mathrm{CH}^{\mathrm{a}}$ & UK \\
\hline \multicolumn{6}{|l|}{ Fracture history } \\
\hline $\begin{array}{l}\text { After hip } \\
\text { fracture }\end{array}$ & Yes & Yes & Yes & $\mathrm{Yes}^{\mathrm{b}}$ & Yes \\
\hline $\begin{array}{l}\text { After vertebral } \\
\text { fracture }^{\mathrm{c}}\end{array}$ & Yes & Yes & Yes & Yes & Yes \\
\hline $\begin{array}{l}\text { After other } \\
\text { fracture }\end{array}$ & Yes & if $\mathrm{T}<-1.8$ & Yes & No & Yes \\
\hline $\begin{array}{l}\mathrm{aBMD} \text { as the } \\
\text { sole criterion }\end{array}$ & $\mathrm{T} \leq-2.5$ & $\mathrm{~T} \leq-2.5$ & $\mathrm{~T} \leq-2.5$ & No & $\mathrm{No}^{\mathrm{d}}$ \\
\hline $\begin{array}{l}\text { Clinical risk } \\
\text { factors only }\end{array}$ & No & No & No & No & \\
\hline $\begin{array}{l}\text { aBMD and } \\
\text { clinical risk } \\
\text { factors }\end{array}$ & $\begin{array}{l}-2.5<\mathrm{T}<-1.0 \text { AND } \\
(\mathrm{MOF} \text { FRAX risk }> \\
20 \%, \text { or HF FRAX } \\
\text { risk }>3 \%)\end{array}$ & $\begin{array}{c}-2.5<\mathrm{T}<-1.5 \text { AND } \\
\text { (MOF FRAX risk }> \\
15 \%, \text { or family } \\
\text { history of HF) }\end{array}$ & NA & $\begin{array}{l}\mathrm{T}<-2.0 \text { AND } \\
\quad(10 \text {-yr risk of } \mathrm{HF} \\
\quad \text { or } \mathrm{VF} \geq \text { risk of } \\
74 \text {-yr-old woman })\end{array}$ & $\begin{array}{l}\text { Age }<70 \text { : if risk } \geq \text { risk of women of the same } \\
\text { age with prior fragility fracture; Age } \geq 70 \text { : if } \\
\text { risk } \geq \text { risk of women age } 70 \text { with prior } \\
\text { fragility fracture }\end{array}$ \\
\hline $\begin{array}{l}\text { Glucocorticoid } \\
\text { therapy (oral } \\
\text { intake for } \geq 3 \\
\text { months) }\end{array}$ & Not specified & Not specified & $\begin{array}{l}\geq 2.5 \\
\mathrm{mg} / \mathrm{d} \\
\text { if } \\
\mathrm{DXA} \\
\mathrm{T} \leq- \\
1.5\end{array}$ & $\begin{aligned} \geq & 7.5 \mathrm{mg} / \mathrm{d} \text { if DXA T } \\
& \leq-1.5\end{aligned}$ & $\geq 7.5 \mathrm{mg} / \mathrm{d}$ \\
\hline
\end{tabular}

$D$ - $A$ - $C H$, Germany, Austria, Switzerland; $U K$, United Kingdom; $a B M D$, areal bone mineral density; $D X A$, dual X-ray absorptiometry; $F R A X ®$, fracture risk assessment tool (www.shef.ac.uk/FRAX); $M O F$, major osteoporotic fracture; $H F$, hip fracture; $V F$, vertebral fracture; $y r$, year; $N A$, not applicable; $m g / d$, milligrams per day

${ }^{a}$ Includes German-speaking populations (Germany, Austria, and German-speaking Switzerland)

${ }^{\mathrm{b}}$ aBMD with T-score $<-2$ recommended but immediate initiation of therapy without DXA measurement accepted

${ }^{\mathrm{c}}$ Vertebral fractures confirmed by radiography

${ }^{\mathrm{d}} \mathrm{aBMD}$ alone is not recommended for a population-based screen for osteoporosis case-finding. aBMD should be used in addition to risk factors, importantly age. A risk assessment by FRAX® is preferred over QFracture

Notably, there is a need to further address and improve case-finding strategies among men. In China and South Korea, there was a 5-year age difference between men and women when considering the threshold for DXA assessment in the absence of fracture. For DXA interpretation, some approaches, including FRAX®, use female reference data for men and women, while DXA manufacturers generally provide gender-specific reference ranges. Thus, as most research informing diagnostic and treatment guidelines has been on post-menopausal women, further research on men and premenopausal women is required.

\section{Conclusions}

Most recently, the emphasis on adequate identification for those in most urgent need of therapy has led to the establishment of fracture liaison services, pursuing strategies of tertiary prevention. However, preventing the first fracture remains a most important goal, in part since the occurrence of fractures strongly increases the risk of sustaining additional fractures. Approaches for case- finding and the threshold for initiating osteoporosisspecific medication differ across countries. Therefore, more refined ways of addressing the needs of patients with osteoporosis are urgently needed, in both the Eastern and the Western countries.

Acknowledgments The authors acknowledge all contributors to the Eastmeets-West symposium at the Annual European Calcified Tissue Society (ECTS) Scientific Meeting in Valencia 2018. We further thank Dr. Weibo Xia, Dr. Dong-Won Byun, Dr. Ye Soo Park, and Dr. Salvatore Minisola for their support of the East-meets-West working group and ongoing program at the annual ECTS conference. Finally, we thank the ECTS Clinical Action Group for their input on this manuscript.

Funding Open access funding provided by Swiss Federal Institute of Technology Zurich.

Data availability Not applicable

\section{Compliance with ethical standards}

Conflicts of interest AMB has no conflicts of interest to declare. YT has received speaking fees and/or honoraria from Daiichi-Sankyo, Astellas, Chugai, Eli Lilly, Abbvie, YL Biologics, Bristol-Myers, Takeda, 
Mitsubishi-Tanabe, Novartis, Eisai, Janssen, and Teijin. He has also received research grants from Asahi-Kasei, Mitsubischi-Tanabe, Chugai, Takeda, Sanofi, Bristol-Myers, UCB, Daiichi-Sankyo, Eisai, and Ono. LX has no conflicts of interest to report. Y-CH has no conflicts of interest to report. EM reports grants and/or personal fees from Amgen, Consilient Health, Fresenius Kabi, MSD, Novartis, Roche, AgNovos, Internis, and REDX Pharma outside the submitted work. SRC reports consulting fees from Amgen, Radius, and Myovant and grants support and speaking fees from Amgen. CCG reports consulting fees from AgNovos Healthcare and Mindways Software, Inc. and research funding from AgNovos.

\section{Code availability Not applicable}

Open Access This article is licensed under a Creative Commons Attribution-NonCommercial 4.0 International License, which permits any non-commercial use, sharing, adaptation, distribution and reproduction in any medium or format, as long as you give appropriate credit to the original author(s) and the source, provide a link to the Creative Commons licence, and indicate if changes were made. The images or other third party material in this article are included in the article's Creative Commons licence, unless indicated otherwise in a credit line to the material. If material is not included in the article's Creative Commons licence and your intended use is not permitted by statutory regulation or exceeds the permitted use, you will need to obtain permission directly from the copyright holder. To view a copy of this licence, visit http:// creativecommons.org/licenses/by-nc/4.0/.

\section{References}

1. Leslie WD, Morin SN (2014) Osteoporosis epidemiology 2013: implications for diagnosis, risk assessment, and treatment. Curr Opin Rheumatol 26:440-446. https://doi.org/10.1097/BOR. 0000000000000064

2. Wright NC, Looker AC, Saag KG, Curtis JR, Delzell ES, Randall S, Dawson-Hughes B (2014) The recent prevalence of osteoporosis and low bone mass in the United States based on bone mineral density at the femoral neck or lumbar spine. J Bone Miner Res 29:2520-2526. https://doi.org/10.1002/jbmr.2269

3. World Demographics Profile 2018. https://www.indexmundi.com/ world/demographics profile.html. Accessed 1 May 2019

4. Johnell O, Kanis JA (2006) An estimate of the worldwide prevalence and disability associated with osteoporotic fractures. Osteoporos Int 17:1726-1733. https://doi.org/10.1007/s00198006-0172-4

5. Nikitovic M, Wodchis WP, Krahn MD, Cadarette SM (2013) Direct health-care costs attributed to hip fractures among seniors: a matched cohort study. Osteoporos Int 24:659-669. https://doi. org/10.1007/s00198-012-2034-6

6. Morin S, Lix LM, Azimaee M, Metge C, Caetano P, Leslie WD (2011) Mortality rates after incident non-traumatic fractures in older men and women. Osteoporos Int 22:2439-2448. https://doi.org/10. 1007/s00198-010-1480-2

7. Cummings SR, Eastell R (2020) Stop (mis)classifying fractures as high- or low-trauma or as fragility fractures. Osteoporos Int 31 : 1023-1024

8. Bougioukli S, Kollia P, Koromila T, Varitimidis S, Hantes M, Karachalios T, Malizos KN, Dailiana ZH (2019) Failure in diagnosis and under-treatment of osteoporosis in elderly patients with fragility fractures. J Bone Miner Metab 37:327-335. https://doi. org/10.1007/s00774-018-0923-2

9. Solomon DH, Johnston SS, Boytsov NN, McMorrow D, Lane JM, Krohn KD (2014) Osteoporosis medication use after hip fracture in
U.S. patients between 2002 and 2011. J Bone Miner Res 29:19291937. https://doi.org/10.1002/jbmr.2202

10. Desai RJ, Mahesri M, Abdia Y, Barberio J, Tong A, Zhang D, Mavros P, Kim SC, Franklin JM (2018) Association of osteoporosis medication use after hip fracture with prevention of subsequent nonvertebral fractures. JAMA Netw Open 1:e180826. https://doi. org/10.1001/jamanetworkopen.2018.0826

11. Bauer DC (2018) Osteoporosis treatment after hip fracture: bad news and getting worse. JAMA Netw Open 1:e180844

12. Harvey NCW, McCloskey EV, Mitchell PJ, Dawson-Hughes B, Pierroz DD, Reginster JY, Rizzoli R, Cooper C, Kanis JA (2017) Mind the (treatment) gap: a global perspective on current and future strategies for prevention of fragility fractures. Osteoporos Int 28: $1507-1529$

13. Xia W, Cooper C, Li M, Xu L, Rizzoli R, Zhu M, Lin H, Beard J, Ding Y, Yu W, Cavalier E, Zhang Z, Kanis JA, Cheng Q, Wang Q, Reginster JY (2019) East meets West: current practices and policies in the management of musculoskeletal aging. Aging Clin Exp Res 31:1351-1373. https://doi.org/10.1007/s40520-019-01282-8

14. Kanis JA, McCloskey EV, Johansson H, Oden A, Melton LJ III, Khaltaev N (2008) A reference standard for the description of osteoporosis. Bone 42:467-475

15. Kanis JA, McCloskey EV, Johansson H et al (2013) European guidance for the diagnosis and management of osteoporosis in postmenopausal women. Osteoporos Int 24:23-57. https://doi.org/ 10.1007/s00198-012-2074-y

16. Sözen T, Özışık L, Başaran NÇ (2017) An overview and management of osteoporosis. Eur J Rheumatol 4:46-56. https://doi.org/10. 5152/eurjrheum.2016.048

17. Stone KL, Seeley DG, Lui LY, Cauley JA, Ensrud K, Browner WS, Nevitt MC, Cummings SR, Osteoporotic Fractures Research Group (2003) BMD at multiple sites and risk of fracture of multiple types: long-term results from the study of osteoporotic fractures. J Bone Miner Res 18:1947-1954. https://doi.org/10.1359/jbmr.2003.18. 11.1947

18. Siris ES, Chen YT, Abbott TA, Barrett-Connor E, Miller PD, Wehren LE, Berger ML (2004) Bone mineral density thresholds for pharmacological intervention to prevent fractures. Arch Intern Med 164:1108-1112. https://doi.org/10.1001/archinte.164.10. 1108

19. Shepstone L, Lenaghan E, Cooper C, Clarke S, Fong-Soe-Khioe R, Fordham R, Gittoes N, Harvey I, Harvey N, Heawood A, Holland R, Howe A, Kanis J, Marshall T, O'Neill T, Peters T, Redmond N, Torgerson D, Turner D, McCloskey E, Shepstone L, Lenaghan E, Cooper C, Clarke S, Fong-Soe-Khioe R, Fordham R, Gittoes N, Harvey I, Harvey N, Heawood A, Holland R, Howe A, Kanis J, Marshall T, O'Neill T, Peters T, Redmond N, Torgerson D, Turner D, McCloskey E, Crabtree N, Duffy H, Parle J, Rashid F, Stant K, Taylor K, Thomas C, Knox E, Tenneson C, Williams H, Adams D, Bion V, Blacklock J, Dyer T, Bratherton S, Fidler M, Knight K, McGurk C, Smith K, Young S, Collins K, Cushnaghan J, Arundel C, Bell K, Clark L, Collins S, Gardner S, Mitchell N (2018) Screening in the community to reduce fractures in older women (SCOOP): a randomised controlled trial. Lancet 391:741-747. https://doi.org/10.1016/S0140-6736(17)32640-5

20. McCloskey E, Johansson H, Harvey NC, Shepstone L, Lenaghan E, Fordham R, Harvey I, Howe A, Cooper C, Clarke S, Gittoes N, Heawood A, Holland R, Marshall T, O'Neill TW, Peters TJ, Redmond N, Torgerson D, Kanis JA, the SCOOP Study Team (2018) Management of patients with high baseline hip fracture risk by FRAX reduces hip fractures - a post hoc analysis of the SCOOP study. J Bone Miner Res 33:1020-1026. https://oi.org/10.1002/ jbmr.3411

21. Rubin KH, Rothmann MJ, Holmberg T, Høiberg M, Möller S, Barkmann R, Glüer CC, Hermann AP, Bech M, Gram J, Brixen K (2018) Effectiveness of a two-step population-based osteoporosis 
screening program using FRAX: the randomized Risk-stratified Osteoporosis Strategy Evaluation (ROSE) study. Osteoporos Int 29:567-578. https://doi.org/10.1007/s00198-017-4326-3

22. Rubin KH, Holmberg T, Rothmann MJ, Høiberg M, Barkmann R, Gram J, Hermann AP, Bech M, Rasmussen O, Glüer CC, Brixen K (2015) The Risk-Stratified Osteoporosis Strategy Evaluation study (ROSE): a randomized prospective population-based study. Design and Baseline Characteristics. Calcif Tissue Int 96:167-179. https:// doi.org/10.1007/s00223-014-9950-8

23. Merlijn T, Swart KM, Schoor NM et al (2019) The effect of a screening and treatment program for the prevention of fractures in older women: a randomized pragmatic trial. J Bone Miner Res 34: 1993-2000. https://doi.org/10.1002/jbmr.3815

24. McCloskey E, Harvey N, Johansson H, Lorentzon M, Vandenput L, Kanis JA (2020) Screening for high fracture risk. Osteoporos Int 31:1179-1180. https://doi.org/10.1007/s00198-020-05416-x

25. Kanis JA, Harvey N, Cooper C et al (2016) A systematic review of intervention thresholds based on FRAX: a report prepared for the National Osteoporosis Guideline Group and the International Osteoporosis Foundation. Arch Osteoporos 11:25

26. Wu Q, Xiao X, Xu Y (2020) Performance of FRAX in predicting fractures in US postmenopausal women with varied race and genetic profiles. J Clin Med 9:285. https://doi.org/10.3390/jcm9010285

27. Kanis JA, Hans D, Cooper C et al (2011) Interpretation and use of FRAX in clinical practice. Osteoporos Int 22:2395-2411. https:// doi.org/10.1007/s00198-011-1713-z

28. Bow CH, Cheung E, Cheung CL, Xiao SM, Loong C, Soong C, Tan KC, Luckey MM, Cauley JA, Fujiwara S, Kung AWC (2012) Ethnic difference of clinical vertebral fracture risk. Osteoporos Int 23:879-885. https://doi.org/10.1007/s00198-011-1627-9

29. Yang N-P, Lin T, Wang C-S, Chou P (2003) Community-based survey of low quantitative ultrasound values of calcaneus in Taiwan. J Clin Densitom 6:131-141. https://doi.org/10.1385/JCD: $6: 2: 131$

30. Kwok T, Khoo CC, Leung J, Kwok A, Qin L, Woo J, Leung PC (2012) Predictive values of calcaneal quantitative ultrasound and dual energy $\mathrm{X}$ ray absorptiometry for non-vertebral fracture in older men: results from the MrOS study (Hong Kong). Osteoporos Int 23: 1001-1006. https://doi.org/10.1007/s00198-011-1634-x

31. Cheung EYN, Tan KCB, Cheung C-L, Kung AWC (2016) Osteoporosis in East Asia: current issues in assessment and management. Osteoporos Sarcopenia 2:118-133. https://doi.org/10. 1016/J.AFOS.2016.07.001

32. Xia W-B, He S-L, Xu L, Liu AM, Jiang Y, Li M, Wang O, Xing XP, Sun Y, Cummings SR (2012) Rapidly increasing rates of hip fracture in Beijing, China. J Bone Miner Res 27:125-129. https:// doi.org/10.1002/jbmr.519

33. Chinese Society of Osteoporosis and Bone and Mineral Research. http://www.csobmr.org.cn/. Accessed 30 May 2019

34. IOF one-minute risk assessment. http://riskcheck.iofbonehealth. org/. Accessed 30 May 2019

35. Koh LK, Sedrine WB, Torralba TP, Kung A, Fujiwara S, Chan SP, Huang QR, Rajatanavin R, Tsai KS, Park HM, Reginster JY, Osteoporosis Self-Assessment Tool for Asians (OSTA) Research Group (2001) A simple tool to identify asian women at increased risk of osteoporosis. Osteoporos Int 12:699-705

36. Sato M, Vietri J, Flynn JA, Fujiwara S (2014) Treatment for osteoporosis among women in Japan: associations with patient characteristics and patient-reported outcomes in the 2008-2011 Japan National Health and Wellness Surveys. J Osteoporos 2014:1-9. https://doi.org/10.1155/2014/909153

37. Iki M (2012) Epidemiology of osteoporosis in Japan. Clin Calcium 22:797-803 CliCa1206797803

38. Cheung C-L, Ang SB, Chadha M, Chow ES-L, Chung Y-S, Hew FL, Jaisamrarn U, Ng H, Takeuchi Y, Wu C-H, Xia W, Yu J, Fujiwara S (2018) An updated hip fracture projection in Asia:
The Asian federation of osteoporosis societies study. Osteoporos Sarcopenia 4: 16-2. https://doi.org/10.1016/j.afos.2018.03.003

39. Orimo H, Nakamura T, Hosoi T, Iki M, Uenishi K, Endo N, Ohta H, Shiraki M, Sugimoto T, Suzuki T, Soen S, Nishizawa Y, Hagino H, Fukunaga M, Fujiwara S (2012) Japanese 2011 guidelines for prevention and treatment of osteoporosis - executive summary. Arch Osteoporos 7:3-20. https://doi.org/10.1007/s11657-0120109-9

40. Fujiwara S, Nakamura T, Orimo H, Hosoi T, Gorai I, Oden A, Johansson H, Kanis JA (2008) Development and application of a Japanese model of the WHO fracture risk assessment tool (FRAX). Osteoporos Int 19:429-435. https://doi.org/10.1007/s00198-0070544-4

41. Soen S, Fukunaga M, Sugimoto T et al (2013) Diagnostic criteria for primary osteoporosis: year 2012 revision. J Bone Miner Metab 31:247-257. https://doi.org/10.1007/s00774-013-0447-8

42. Ha YC, Park YG, Nam KW, Kim SR (2015) Trend in hip fracture incidence and mortality in Korea: a prospective cohort study from 2002 to 2011. J Korean Med Sci 30:483-488. https://doi.org/10. 3346/jkms.2015.30.4.483

43. Aging population in South Korea could put strain on healthcare costs. https://www5.aaos.org/News/DailyEdition2019/Friday/ 010/?ssopc $=1$. Accessed 31 Aug 2020

44. Ha Y-C, Kim T-Y, Lee A, Lee YK, Kim HY, Kim JH, Park CM, Jang $S$ (2016) Current trends and future projections of hip fracture in South Korea using nationwide claims data. Osteoporos Int 27: 2603-2609. https://doi.org/10.1007/s00198-016-3576-9

45. Park C, Jang S, Lee A et al (2015) Incidence and mortality after proximal humerus fractures over 50 years of age in South Korea: national claim data from 2008 to 2012. J Bone Metab 22:17-21. https://doi.org/10.11005/jbm.2015.22.1.17

46. Kim TY, Jang S, Park CM, Lee A, Lee YK, Kim HY, Cho EH, Ha YC (2016) Trends of incidence, mortality, and future projection of spinal fractures in Korea using nationwide claims data. J Korean Med Sci 31:801-805. https://doi.org/10.3346/jkms.2016.31.5.801

47. Kwon GD, Jang S, Lee A, Park CM, Lee YK, Kim TY, Kim HY, Park EJ, Ha YC (2016) Incidence and mortality after distal radius fractures in adults aged 50 years and older in Korea. J Korean Med Sci 31:630-634. https://doi.org/10.3346/jkms.2016.31.4.630

48. Ha Y-C, Kim H-Y, Jang S, Lee YK, Kim TY (2017) Economic burden of osteoporosis in South Korea: claim data of the National Health Insurance Service from 2008 to 2011. Calcif Tissue Int 101: 623-630. https://doi.org/10.1007/s00223-017-0320-1

49. Physician's guide for diagnosis and treatment of osteoporosis. http://www.ksbmr.org/journal/index4.php. Accessed 30 May 2019

50. Yoo DH, Hrycaj P, Miranda P, Ramiterre E, Piotrowski M, Shevchuk S, Kovalenko V, Prodanovic N, Abello-Banfi M, Gutierrez-Ureña S, Morales-Olazabal L, Tee M, Jimenez R, Zamani O, Lee SJ, Kim HU, Park W, Müller-Ladner U (2013) A randomised, double-blind, parallel-group study to demonstrate equivalence in efficacy and safety of CT-P13 compared with innovator infliximab when coadministered with methotrexate in patients with active rheumatoid arthritis: the PLANETRA study. Ann Rheum Dis 72:1613-1620. https://doi.org/10.1136/annrheumdis2012-203090

51. Park SY, Gong HS, Kim KM et al (2018) Korean guideline for the prevention and treatment of glucocorticoid-induced osteoporosis. J Bone Metab 25:195-211. https://doi.org/10.11005/jbm.2018.25.4. 195

52. Hernlund E, Svedbom A, Ivergård M, Compston J, Cooper C, Stenmark J, McCloskey EV, Jönsson B, Kanis JA (2013) Osteoporosis in the European Union: medical management, epidemiology and economic burden: A report prepared in collaboration with the International Osteoporosis Foundation (IOF) and the European Federation of Pharmaceutical Industry Associations 
(EFPIA). Arch Osteoporos 8:136. https://doi.org/10.1007/s11657013-0136-1

53. Broken Bones, Broken Lives International Osteoporosis Foundation. https://www.iofbonehealth.org/broken-bones-brokenlives. Accessed 13 Jun 2019

54. Kanis JA, Cooper C, Rizzoli R et al (2019) Executive summary of the European guidance for the diagnosis and management of osteoporosis in postmenopausal women. Calcif Tissue Int 104:235238. https://doi.org/10.1007/s00223-018-00512-x

55. Compston J, Cooper A, Cooper C et al (2017) UK clinical guideline for the prevention and treatment of osteoporosis. Arch Osteoporos 12:43. https://doi.org/10.1007/s11657-017-0324-5

56. McCloskey E, Kanis JA, Johansson H, Harvey N, Odén A, Cooper A, Cooper C, Francis RM, Reid DM, Marsh D, Selby P, Thompson F, Hewitt S, Compston J (2015) FRAX-based assessment and intervention thresholds - an exploration of thresholds in women aged 50 years and older in the UK. Osteoporos Int 26:2091-2099. https:// doi.org/10.1007/s00198-015-3176-0

57. Thomasius F, Baum E, Bernecker P, Böcker W, Brabant T, Clarenz P, Demary W, Dimai HP, Engelbrecht M, Engelke K, Fratermann U, Grieser T, Gulich M, Hadji P, Henning J, Jehle PM, Kern PM, Ketteler M, Klatt G, Kraenzlin M, Maus U, Meier C, Moser U, Müller D, Peichl P, Pfeifer M, Rintelen B, Rueger JM, Schober HC, Schöffel D, Schwarz H, Siggelkow H, Suhm N, Wiese KG, Wörtler K, Kurth AA (2018) DVO Leitlinie 2017 zur Prophylaxe, Diagnostik und Therapie der Osteoporose bei postmenopausalen Frauen und Männern. Osteologie 27:154-160. https://doi.org/10. 1055/s-0038-1673537

58. Japan Cancer Society. https://www.jcancer.jp/wp-content/uploads/ jcancer_e_20171127.pdf. Accessed 5 Dec 2019

59. Singer A, Exuzides A, Spangler L, O’Malley C, Colby C, Johnston K, Agodoa I, Baker J, Kagan R (2015) Burden of illness for osteoporotic fractures compared with other serious diseases among postmenopausal women in the United States. Mayo Clin Proc 90: 53-62. https://doi.org/10.1016/j.mayocp.2014.09.011

60. Nordström P, Toots A, Gustafson Y, Thorngren KG, Hommel A, Nordström A (2017) Bisphosphonate use after hip fracture in older adults: a nationwide retrospective cohort study. J Am Med Dir Assoc 18:515-521. https://doi.org/10.1016/j.jamda.2016.12.083

61. Silva BC, Leslie WD, Resch H, Lamy O, Lesnyak O, Binkley N, McCloskey EV, Kanis JA, Bilezikian JP (2014) Trabecular bone score: a noninvasive analytical method based upon the DXA image. J Bone Miner Res 29:518-530. https://doi.org/10.1002/jbmr.2176

62. McCloskey EV, Odén A, Harvey NC, Leslie WD, Hans D, Johansson H, Barkmann R, Boutroy S, Brown J, Chapurlat R, Elders PJM, Fujita Y, Glüer CC, Goltzman D, Iki M, Karlsson M, Kindmark A, Kotowicz M, Kurumatani N, Kwok T, Lamy O, Leung J, Lippuner K, Ljunggren Ö, Lorentzon M, Mellström D, Merlijn T, Oei L, Ohlsson C, Pasco JA, Rivadeneira F, Rosengren B, Sornay-Rendu E, Szulc P, Tamaki J, Kanis JA (2016) A metaanalysis of trabecular bone score in fracture risk prediction and its relationship to FRAX. J Bone Miner Res 31:940-948. https://doi. org/10.1002/jbmr.2734

63. Choi YJ, Chung Y-S (2016) Type 2 diabetes mellitus and bone fragility: special focus on bone imaging. Osteoporos Sarcopenia 2:20-24. https://doi.org/10.1016/j.afos.2016.02.001

64. Bonaccorsi G, Messina C, Cervellati C, Maietti E, Medini M, Rossini M, Massari L, Greco P (2018) Fracture risk assessment in postmenopausal women with diabetes: comparison between DeFRA and FRAX tools. Gynecol Endocrinol 34:404-408. https://doi.org/10.1080/09513590.2017.1407308

65. Geusens P, Eisman JA, SInger A, van den Bergh J (2018) Fracture Liaison Service. In: Bilezikian JP, Bouillon R, Clemns T, Compston J, Bauer DC, Ebeling PR, Engelke K, Goltzman D, Guise T, Jan de Beur SM, Jüppner H, Lyons K, McCauley L,
McClung MR, Miller PD, Papapoulos SE, Roodman GD, Rosen CJ, Seeman E, Thakker RV, Whyte MP, Zaidi M (Eds) Primer on the metabolic bone diseases and disorders of mineral metabolism, 9th edn. Wiley, New York, pp 405-411

66. Åkesson K, Marsh D, Mitchell PJ et al (2013) Capture the fracture: a best practice framework and global campaign to break the fragility fracture cycle. Osteoporos Int 24:2135-2152. https://doi.org/10. 1007/s00198-013-2348-Z

67. Lems WF, Dreinhöfer KE, Bischoff-Ferrari H, Blauth M, Czerwinski E, da Silva JAP, Herrera A, Hoffmeyer P, Kvien T, Maalouf G, Marsh D, Puget J, Puhl W, Poor G, Rasch L, Roux C, Schüler S, Seriolo B, Tarantino U, van Geel T, Woolf A, Wyers C, Geusens P (2017) EULAR/EFORT recommendations for management of patients older than 50 years with a fragility fracture and prevention of subsequent fractures. Ann Rheum Dis 76:802-810. https://doi.org/10.1136/annrheumdis-2016-210289

68. (WHO) (2003) Prevention and management of osteoporosis. In: World Health Organ. Tech. Rep. Ser. http://apps.who.int/iris/ bitstream/handle/10665/42841/WHO_TRS_921.pdf?sequence= 1\&ua=1. Accessed 5 Dec 2019

69. Wu C-H, Tu S-T, Chang Y-F, Chan DC, Chien JT, Lin CH, Singh S, Dasari M, Chen JF, Tsai KS (2018) Fracture liaison services improve outcomes of patients with osteoporosis-related fractures: a systematic literature review and meta-analysis. Bone 111:92-100. https://doi.org/10.1016/J.BONE.2018.03.018

70. Hagino H, Wada T (2019) Osteoporosis liaison service in Japan. Osteoporos Sarcopenia 5:65-68. https://doi.org/10.1016/j.afos. 2019.09.003

71. Cha YH, Ha YC, Lim JY (2019) Establishment of fracture liaison service in Korea: Where is it stand and where is it going? J Bone Metab 26:207-211. https://doi.org/10.11005/jbm.2019.26.4.207

72. Mithal D (2009) The asian audit: Epidemiology, costs and burden of osteoporosis in Asia 2009. International Osteoporosis Foundation. https://www.iofbonehealth.org/sites/default/files/ PDFs/AuditAsia/Asian_regional_audit_2009.pdf. Accessed 05 Dec 2019c

73. Orwoll E, Blank JB, Barrett-Connor E, Cauley J, Cummings S, Ensrud K, Lewis C, Cawthon PM, Marcus R, Marshall LM, McGowan J, Phipps K, Sherman S, Stefanick ML, Stone K (2005) Design and baseline characteristics of the osteoporotic fractures in men (MrOS) study - a large observational study of the determinants of fracture in older men. Contemp Clin Trials 26: 569-585. https://doi.org/10.1016/j.cct.2005.05.006

74. Cawthon PM, Shahnazari M, Orwoll ES, Lane NE (2016) Osteoporosis in men: findings from the Osteoporotic Fractures in Men Study (MrOS). Ther Adv Musculoskelet Dis 8:15-27. https:// doi.org/10.1177/1759720X15621227

75. Kwok TCY, Su Y, Khoo CC, Leung J, Kwok A, Orwoll E, Woo J, Leung PC (2017) Predictors of non-vertebral fracture in older Chinese males and females: Mr. OS and Ms. OS (Hong Kong). J Bone Miner Metab 35:330-337. https://doi.org/10.1007/s00774016-0761-Z

76. Cronholm F, Rosengren BE, Nilsson JA, Ohlsson C, Mellström D, Ribom E, Karlsson MK (2019) The fracture predictive ability of a musculoskeletal composite score in old men - data from the MrOs Sweden study. BMC Geriatr 19:90. https://doi.org/10.1186/ s12877-019-1106-2

77. Liu J, Curtis EM, Cooper C, Harvey NC (2019) State of the art in osteoporosis risk assessment and treatment. J Endocrinol Investig 42:1149-1164. https://doi.org/10.1007/s40618-019-01041-6

Publisher's note Springer Nature remains neutral with regard to jurisdictional claims in published maps and institutional affiliations. 